\title{
Differences in postoperative complications and prognosis of sacrococcygeal teratoma and presacral tumors in Currarino syndrome
}

Tsuyoshi Sakurai* ${ }^{*}$, Masatoshi Hashimoto, Megumi Nakamura and Naobumi Endo

\begin{abstract}
Background: While sacrococcygeal teratoma (SCT) is a tumor originating from the tip of the sacrum, presacral tumors are accompanied by Currarino syndrome (CS) and classified as the Altman's type IV sacrococcygeal tumors. They are quite different in their pathologies despite the similar location. To the best of our knowledge, there are no published reports comparing their prognosis; therefore, we analyzed their postoperative results and long-term prognosis. Twenty patients with SCT, including CS, who were being followed up at the outpatient clinic of the Department of Pediatric Surgery, Miyagi Children's Hospital between 2004 and 2020, were enrolled in the study. Patients were divided into two groups: those who developed SCT without anorectal malformation and sacral dysplasia, and those who developed presacral tumors with anorectal malformation or sacral dysplasia as CS. Patient records were retrospectively reviewed for clinical details, postoperative complications, and long-term prognosis.

Results: Tethered cord syndrome occurred significantly more frequently in the CS group $(p=0.0108)$. However, no significant differences were observed for malformations other than tethered cord syndrome. Early complications in the CS group were significantly higher than those in the SCT group $(p=0.023)$; the most common complication was dysuria. Regarding long-term prognosis, $70 \%$ of patients in the CS group complained of defecation disorders, which was significantly higher than that in the SCT group $(p=0.0198)$. Voiding dysfunction was also more common in the CS group.

Conclusions: There were significant differences between SCT and CS regarding the rate of development of tethered cord syndrome, short-term postoperative complications, and long-term prognosis. Thus, they are different diseases with the only commonality being the presence of a sacrococcygeal tumor. Furthermore, this study indicated that the background and prognosis of the two conditions were also quite different.
\end{abstract}

Keywords: Sacrococcygeal teratoma, Currarino syndrome, Long-term outcome, Postoperative complication, Sacral agenesis

\section{Background}

Sacrococcygeal teratoma (SCT) is a rare tumor, occurring in 35,000 to 40,000 births [1], with a male-to-female ratio of 1:3-4 [2]. SCT is the most frequent tumor in newborns, when stillbirths are also considered [3]. It can become extremely large, cause massive bleeding and

\footnotetext{
*Correspondence: sakurai@ped-surg.med.tohoku.ac.jp Department of Pediatric Surgery, Miyagi Children's Hospital, Sendai 989-3126, Japan
}

high-output heart failure, and be fatal [4-6]. Even after tumor resection and reduction from the acute phase, in some cases, long-term recurrence, malignant transformations, defecation disorders, urinary disorders, and lower limb movement disorders may develop [7-10]. The functional prognosis of SCT is diverse. Urologic functional disorders occur in $14-51 \%$ of cases and defecation disorders occur in $0-47 \%$ of cases $[7,8,11,12]$.

Currarino syndrome (CS) is well recognized by the Currarino triad of anorectal malformations, sacral 
abnormalities, and presacral tumors [13]. Presacral tumors have no strict definition and are often treated as part of the Altman classification of type IV SCT [14]. The surgical strategy for CS is tumor resection and anorectoplasty. However, there are few reports on the postoperative outcomes and prognosis. Yoshida et al. [15] reported that $40 \%$ of patients with CS remained severely constipated after surgery, ultimately requiring an appendicostomy for antegrade colonic irrigation, and that the true incidence of constipation may be significantly higher than previously thought, because of the different levels of recognition of ongoing symptoms. Lee et al. [16] reported that $83 \%$ of patients with CS who underwent surgery had voiding complaints, postoperatively. Since the severity and incidence show dissimilarities from the SCT findings reported thus far, despite tumor resection at the same site, we hypothesized that the prognosis may differ between SCT and CS. To the best of our knowledge, no studies have directly compared CS and SCT; therefore, we classified patients with CS as having sacral dysplasia or anorectal malformations and SCT without comorbidities, and analyzed their postoperative outcomes and long-term prognosis.

\section{Methods}

\section{Patient population and data collection}

Twenty-three patients with SCT, including CS, who were being followed up at the outpatient clinic of the Department of Pediatric Surgery, Miyagi Children's Hospital between 2004 and 2020, were enrolled. The study was approved by the Ethics Committee of Miyagi Children's Hospital and has, therefore, been performed in accordance with the ethical standards laid down in the 1964 Declaration of Helsinki and its later amendments. Written informed consent was not required, as this was a retrospective study using de-identified data.

Of the 23 patients, three were excluded as they had spina bifida, and this comorbidity, by itself, presented with a high degree of neuropathy, such as constipation, dysuria, and lower limb disorder. Twenty patients were divided into two groups: those who developed SCT only without anorectal malformation and sacral dysplasia (SCT group) (Fig. 1), and those who developed presacral tumors with anorectal malformation and/or sacral dysplasia (CS group) (Fig. 2). The patients satisfied the conditions for the Currarino triad were defined as complete CS and the remaining three cases with only sacral hypoplasia and presacral tumor were defined as mild CS [17]. Except for one patient who underwent computed tomography on day 2 in the SCT group, all patients were diagnosed using magnetic resonance imaging. We performed tumor resection and coccygectomy, if the patient had a coccyx, for all patients

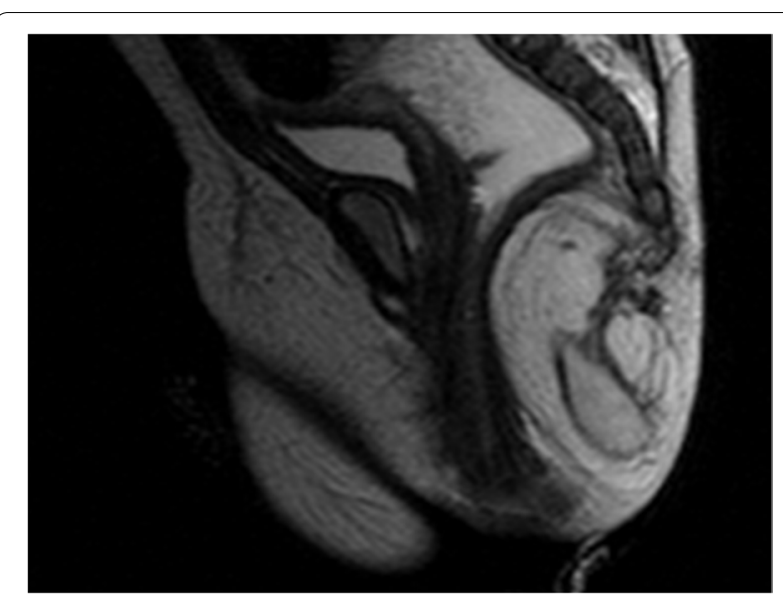

Fig. 1 Sacrococcygeal teratoma on MRI (Altman's type II)

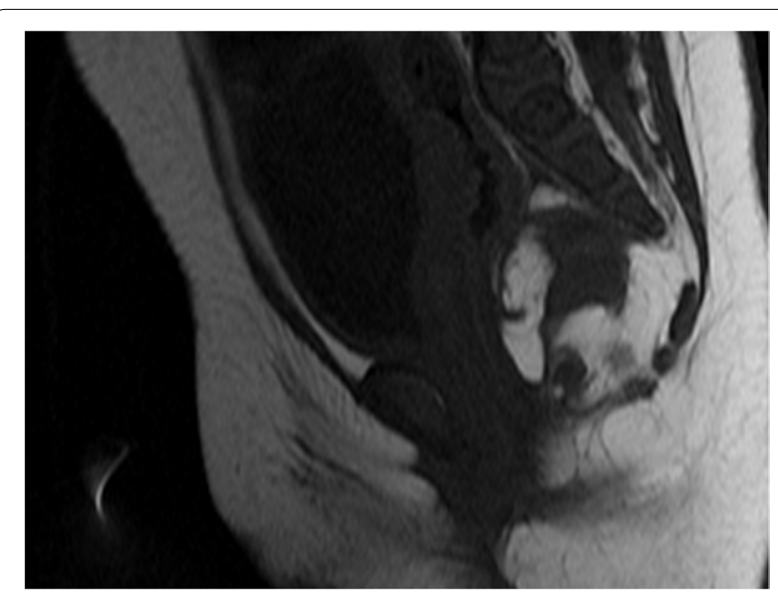

Fig. 2 Presacral teratoma associated with Currarino syndrome on MRI (Altman's type IV)

with SCT, and chose the posterior sagittal approach for tumor resection and anorectoplasty, if necessary. If patients had tethered cord syndrome, untethered cord surgery was performed separately by a pediatric neurosurgeon before surgery for SCT or CS. Disturbance of defecation was defined as refractory constipation requiring medical treatment, including fecal disimpaction or regular use of enemas and/or oral laxatives. Disturbance of urination was defined as uncontrolled voiding, repeated urinary tract infections, bladder emptying problems, or the need for clean intermittent catheterization. Both disturbances were the most recent conditions in the study range. Patient records were retrospectively reviewed for clinical details, such as sex, gestational age, birth weight, comorbidities, radiological and pathological assessment of the tumor, surgical 
factors, postoperative complications, long-term outcomes, and follow-up duration.

\section{Statistical analysis}

The data obtained in this study were assessed using the Wilcoxon rank-sum test or Fisher's exact test for statistical comparison of the two groups. All statistical analyses were performed using the JMP Pro 14 software (SAS

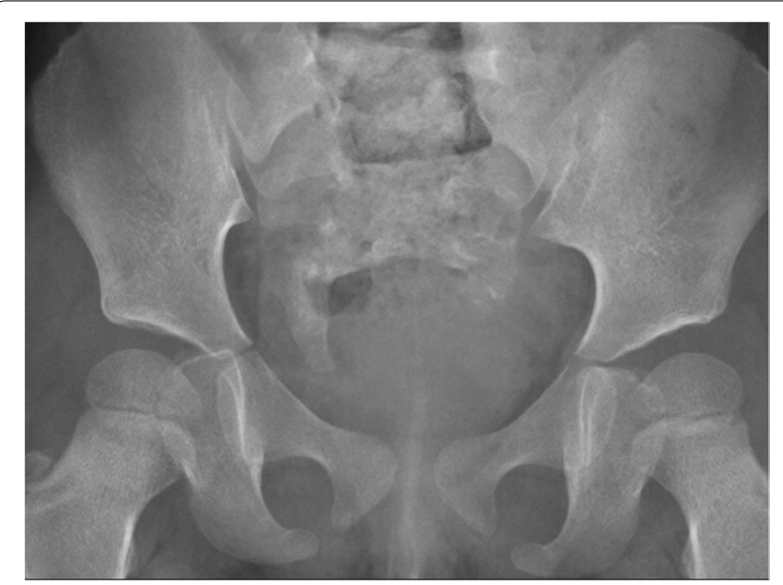

Fig. 3 Radiograph of hemisacrum in Currarino syndrome
Institute Japan Ltd.). Statistical significance was set at $p$ $<0.05$.

\section{Results}

Characteristics of the CS group

All patients in the CS group had sacral hypoplasia, and seven had anorectal malformations. In other words, seven patients were complete CS and the remaining three cases were mild CS. To varying degrees, sacral hypoplasia was unilateral in nine out of 10 cases (Fig. 3); one case was bilateral. Anorectal stenosis accounted for more than half of the anorectal abnormalities observed, a characteristic of CS called "funnel anus."

\section{Background and perioperative factors of the SCT and CS groups}

Table 1 summarizes the background and perioperative factors of patients with SCT and CS. In both groups, the proportion of female patients was more than twofold that of male patients. All patients were born at term and had an appropriate weight. Tethered cord syndrome occurred significantly more frequently in the CS group $(p=0.0108)$. However, no significant differences were observed for other malformations. The size of the tumor evaluated on imaging was not significantly different between the two groups. All patients in the CS group

Table 1 Background and perioperative factors of patients with SCT and CS

\begin{tabular}{|c|c|c|c|}
\hline & $\mathrm{SCT}(n=10)$ & $\operatorname{CS}(n=10)$ & $p$ value \\
\hline Sex (female:male) & $7: 3$ & $7: 3$ & 1.0 \\
\hline Gestational age (weeks) & $39.3[37.4,41.3]$ & $39.4[37,41]$ & 0.872 \\
\hline Birth weight (kg) & $3[2.79,3.22]$ & $3.24[2.56,4.4]$ & 0.182 \\
\hline Other malformations & $1(10 \%)$ & $4(40 \%)$ & 0.303 \\
\hline Tethered cord syndrome & $0(0 \%)$ & $6(60 \%)$ & $0.0108^{*}$ \\
\hline Size of tumor on image (mm) & $40.5[22,127]$ & $30[13,45]$ & 0.0811 \\
\hline Altmann classification type & I: 5, II: 3, III: 1, IV: 1 & IV: 10 & \\
\hline Pathology of tumor & Mature teratome: 9, immature teratome: 1 & Mature teratome: 7, hamartoma: 2, lipoma: 1 & \\
\hline Age at radical surgery (days) & $45.5[1,1870]$ & $578[24,4341]$ & $0.0277^{*}$ \\
\hline Surgery time (min) & $179[115,373]$ & $397.5[176,483]$ & $0.012^{*}$ \\
\hline Blood loss (g) & $17.5[0,85]$ & $24[6,92]$ & 0.377 \\
\hline \multirow[t]{2}{*}{ Early postoperative complication } & $2(20 \%)$ & $8(80 \%)$ & $0.023^{*}$ \\
\hline & Surgical site infection: 1, residual tumor: 1 & $\begin{array}{l}\text { Dysuria: } 6 \text {, residual tumor: } 2 \text {, wound dehiscence: } \\
1 \text {, urethral injury: } 1 \text {, rectal injury: } 1 \text {, abscess: } 1\end{array}$ & \\
\hline Disturbance of defecation & $1(10 \%)$ & $7(70 \%)$ & $0.0198^{*}$ \\
\hline Disturbance of urination & $0(0 \%)$ & $4(40 \%)$ & 0.0867 \\
\hline Motor dysfunction of the lower extremities & $1(10 \%)$ & $0(0 \%)$ & 1.0 \\
\hline Recurrence of tumor & $0(0 \%)$ & $0(0 \%)$ & 1.0 \\
\hline Follow-up duration (years) & $8.4[0.2,16]$ & $7.9[1.5,12]$ & 0.903 \\
\hline
\end{tabular}

Data are presented as frequency (\%) for qualitative parameters and median [range] for continuous parameters SCT sacrococcygeal teratoma, CS Currarino syndrome ${ }^{*} p<0.05$ 
showed Altman classification type IV, whereas Altman classification type I was more common in the SCT group. In both groups, the pathology was mostly mature teratomas; there was one case of immature teratoma in the SCT group, two of hamartoma, and one of lipoma in the CS group. Due to intractable constipation, colostomy was performed in five patients in the CS group, before radical surgery. Age at radical surgery was significantly higher in the CS group ( $p=0.0277)$. The surgical time was also significantly longer in the CS group $(p=0.012)$. There was no significant difference in the amount of bleeding associated with surgery between the two groups.

Early complications in the CS group were common (80\%); mostly postoperative dysuria, which did not manifest before radical surgery. Of those with early complications, 33\% improved over time, and $67 \%$ had voiding dysfunction. Dysuria was not evident as an early complication in the SCT group. Overall, early complications were significantly more common in the CS group than in the SCT group $(p=0.023)$. Regarding long-term prognosis, $70 \%$ of patients in the CS group complained of defecation disorders; this was significantly higher than that in the SCT group $(p=0.0198)$. Although there was no significant difference in dysuria, it tended to be more common in the CS group. One case of lower limb dyskinesia was observed in the SCT group, which was considered to be largely affected by comorbid neuromuscular disease. There were no recurrent tumors in either group. The median follow-up period for the SCT and CS groups was 8.4 and 7.9 years, respectively, with no significant difference observed between the two groups.

\section{Discussion}

Since SCT and CS are associated with different pathological findings, this study hypothesized that their prognosis is likely to be different. Comorbidities, perioperative factors, and long-term outcomes were significantly different from those of isolated SCTs and presacral tumors in CS. This is the first study to directly compare the background and prognosis of SCT and CS.

In our study, we defined the CS group as having presacral tumors with one or both anorectal malformations and sacral dysplasia. CS with the Currarino triad of anorectal malformations, sacral abnormalities, and presacral tumors was first proposed by Currarino et al. [13] in 1981. The classification of CS was first reported by Martucciello et al. [17] in 2004. According to this classification, our CS group had complete CS in seven cases with Currarino triad and mild CS in three cases with only presacral tumors and sacral dysplasia. Therefore, this study may be regarded as a comparative study of SCT and CS. In recent years, the MNX1 gene was discovered to be responsible for CS, and there are some reports on its penetrability and phenotype diversity [18]. However, there is no clear gene responsible for SCT. Besides, presacral tumors in CS arise from incomplete separation of the endodermal and ectodermal layers during early embryonic development [13]. SCTs originate from pluripotent cells (Hensen's node) located at the tip of the coccyx [19]. Thus, from a developmental perspective, the two tumors should be considered different.

There was no difference in the background characteristics of SCT and CS in terms of sex and perinatal factors, and the results were similar to those reported previously $[20,21]$. CS is associated with some comorbid malformations, with tethered cord syndrome being especially common [22]. In this study, tethered cord syndrome was significantly more common in the CS group. Although there were no significant differences in other comorbid malformations, it was more common in the CS group with three cases of urinary system malformations and one case of body surface malformations. There was one case of neuromuscular disease in the SCT group. The fact that the time to surgery was significantly longer in the CS group may be due to later diagnoses in the CS group compared that in the SCT group. This is because the diagnosis of Altmann classification type IV tumors, such as CS, is often delayed compared to the more easily diagnosed Altmann classification types I-III SCTs. Although, there are reports of CS cases of Altmann classification type II, in this study, all CS cases were Altmann classification type II, actually [23]. Additionally, the diagnosis of CS, especially in cases of mild anorectal malformations, can be easily missed when a small sacral defect is masked by a rectum loaded with stool [22].

Early postoperative complications were significantly more common in the CS group, especially dysuria. Dysuria was transient and improved over time; however, at the time of follow-up, four of the six cases had not yet improved. The main cause is thought to be intraoperative damage to the pelvic plexus. Barakat et al. [24] reported that 15 cases of Altman classification types I-II had no urinary or defecation disorders, but 5 of 7 cases (71\%) of Altman classification types III-IV had urinary disorders, soiling, or constipation [24]. However, there are reports that the complications do not change according to Altmann classification [25], and it may only be a problem when the tumor occupies the deep pelvic region. Regarding long-term outcomes, defecation disorders were significantly more common in the CS group, and dysuria was not significant, but tended to be more common in the CS group. Dewberry et al. [26] reported that compared to patients with isolated SCTs, patients with a presacral mass and anorectal malformation had worse bowel function outcomes. Additionally, it has recently been found that CS is associated with a higher occurrence of 
dysuria than that reported in previous studies [16]. These negative reports on the long-term outcomes of presacral tumors in CS support our findings.

Although no tumor recurrence and similar histology were observed in both groups in our study, SCT is wellknown for its recurrence and malignant transformation. Dirix et al. [27] examined the malignancy and recurrence risk in SCT and presacral tumors associated with CS. Their results showed that in isolated SCTs, the malignancy and recurrence risk were significantly higher in SCT than in CS. This suggests that even if the histological types of the tumors are similar, malignancy may be more common in SCT.

CS is often associated with comorbidities, such as anorectal malformations and tethered cord syndrome. Therefore, it was not possible to make a true comparison between tumors in this study, although low-type anorectal malformations, such as anorectal stenosis and anocutaneous fistulas, are often associated with good postoperative defecation control, and in this study, all tethered cord syndrome cases underwent detethering treatment. Besides, in this study, the number of cases was limited because of the rarity of the disease and the singleinstitution survey. This may be caused by the absence of lower limb disorders and fewer complications in the SCT group in our study than previously reported. Similarly, with regard to long-term outcomes, the follow-up period was 10 years or less, and future large-scale research is required.

\section{Conclusions}

SCT and presacral tumors in CS are different diseases with the only common feature being the presence of a sacrococcygeal tumor. It was not surprising, therefore, that there were significant differences in the rate of development of tethered cord syndrome, short-term postoperative complications, and long-term prognosis, suggesting fairly different pathologies. Further detailed and large-scale research on the pathologies of SCT and CS is required.

\section{Abbreviations}

CS: Currarino syndrome; SCT: Sacrococcygeal teratoma.

\section{Acknowledgements}

We would like to thank Editage (www.editage.com) for their writing support.

\section{Authors' contributions}

T.S., M.H, M.N., and N.E. contributed to the conception and design of this study; T.S. collected data, performed the statistical analysis, and drafted the manuscript; N.E. critically reviewed the manuscript and supervised the whole study process. All authors read and approved the final manuscript.

\section{Funding}

This research did not receive any specific grant from funding agencies in the public, commercial, or not-for-profit sectors.

\section{Availability of data and materials}

The data that support the findings of this study are available from the corresponding author upon reasonable request.

\section{Declarations}

\section{Ethics approval and consent to participate}

This study was approved by the ethics committee of Miyagi Children's Hospital. Written informed consent was not required, as this was a retrospective study using de-identified data.

\section{Consent for publication}

Not applicable

\section{Competing interests}

The authors declare that they have no competing interests.

Received: 30 September 2021 Accepted: 1 December 2021

Published online: 03 March 2022

References

1. Rescorla FJ. Pediatric germ cell tumors. Semin Pediatr Surg. 2012;21:51-60

2. Grosfeld $\mathrm{L}$, Billmire DF. Teratomas in infancy and childhood. Curr Probl Cancer. 1985:9:1-53.

3. Werb P, Scurry J, Ostör A, Fortune D, Attwood H. Survey of congenital tumors in perinatal necropsies. Pathology. 1992;24:247-53.

4. Abraham E, Parray T, Ghafoor A. Complications with massive sacrococcygeal tumor resection on a premature neonate. J Anesth. 2010;24:951-4.

5. Kremer MEB, Wellens LM, Derikx JPM, van Baren R, Heij HA, Wijnen MH, et al. Hemorrhage is the most common cause of neonatal mortality in patients with sacrococcygeal teratoma. J Pediatr Surg. 2016;51:1826-9.

6. Isserman RS, Nelson O, Tran KM, Cai L, Polansky M, Rosenbloom JM, et al. Risk factors for perioperative mortality and transfusion in sacrococcygeal teratoma resections. Paediatr Anaesth. 2017;27:726-32.

7. Masahata K, Ichikawa C, Makino K, Abe T, Kim K, Yamamichi T, et al. Longterm functional outcome of sacrococcygeal teratoma after resection in neonates and infants: a single-center experience. Pediatr Surg Int. 2020;36:1327-32.

8. Rehfuss A, Halleran DR, Aldrink JH, Ching C. Significant rate of lower urinary tract dysfunction in patients with sacrococcygeal teratomas. J Pediatr Urol. 2020;16:546.e1-5.

9. Kremer ME, Derikx JP, van Baren R, Heij HA, Wijnen MH, Wijnen RM, et al. Patient-reported defecation and micturition problems among adults treated for sacrococcygeal teratoma during childhood - the need for new surveillance strategies. Pediatr Blood Cancer. 2016;63:690-4.

10. Padilla BE, Vu L, Lee H, MacKenzie T, Bratton B, O'Day M, et al. Sacrococcygeal teratoma: late recurrence warrants long-term surveillance. Pediatr Surg Int. 2017:33:1189-94

11. Partridge EA, Canning D, Long C, Peranteau WH, Hedrick HL, Adzick NS, et al. Urologic and anorectal complications of sacrococcygeal teratomas: prenatal and postnatal predictors. J Pediatr Surg. 2014;49:139-42 discussion 142.

12. Hambraeus $M$, Hagander $L$, Stenström P, Arnbjörnsson E, Börjesson A. Long-term outcome of sacrococcygeal teratoma: a controlled cohort study of urinary tract and bowel dysfunction and predictors of poor outcome. J Pediatr. 2018;198:131-6.e2.

13. Currarino G, Coln D, Votteler T. Triad of anorectal, sacral, and presacral anomalies. AJR Am J Roentgenol. 1981;137:395-8.

14. Altman RP, Randolph JG, Lilly JR. Sacrococcygeal teratoma: American Academy of Pediatrics Surgical Section survey-1973. J Pediatr Surg. 1974:9:389-98.

15. Yoshida A, Maoate K, Blakelock R, Robertson S, Beasley S. Long-term functional outcomes in children with Currarino syndrome. Pediatr Surg Int. 2010;26:677-81.

16. Lee NG, Gana R, Borer JG, Estrada CR, Khoshbin S, Bauer SB. Urodynamic findings in patients with Currarino syndrome. J Urol. 2012;187:2195-200. 
17. Martucciello G, Torre M, Belloni E, Lerone M, Pini Prato A, Cama A, et al. Currarino syndrome: proposal of a diagnostic and therapeutic protocol. J Pediatr Surg. 2004;39:1305-11.

18. Garcia-Barceló MM, Lui VCH, So MT, Miao X, Leon TY, Yuan ZW, et al. MNX1 (HLXB9) mutations in Currarino patients. J Pediatr Surg. 2009:44:1892-8.

19. Moazam F, Talbert JL. Congenital anorectal malformations. Harbingers of sacrococcygeal teratomas. Arch Surg. 1985;120:856-9.

20. Billmire DF, Grosfeld JL. Teratomas in childhood: analysis of 142 cases. J Pediatr Surg. 1986;21:548-51.

21. Tucker AM, Morgenstern P, Diaz D, Sedighim S, Shaul D, Sydorak R, et al. Neurosurgical management of Currarino syndrome: a case series and review of literature. Surg Neurol Int. 2019;10:70.

22. AbouZeid AA, Mohammad SA, Abolfotoh M, Radwan AB, Ismail MMES, Hassan TA. The Currarino triad: what pediatric surgeons need to know. J Pediatr Surg. 2017;52:1260-8.

23. Gupta R, Sharma SB, Mathur P, Goyal RB. Variants of Currarino syndrome: embryological association and review of pertinent literature. Int J Embryol. 2014;2014:1-5.

24. Shalaby MS, Walker G, O'Toole S, Hammond P, Carachi R. The long-term outcome of patients diagnosed with sacrococcygeal teratoma in childhood. A study of a national cohort. Arch Dis Child. 2014;99:1009-13.

25. Barakat MI, Abdelaal SM, Saleh AM. Sacrococcygeal teratoma in infants and children. Acta Neurochir. 2011;153:1781-6.

26. Dewberry L, Peña A, Meyers ML, Mirsky DM, Bischoff A. Differentiating presacral masses in anorectal malformations and isolated sacrococcygeal teratomas. Pediatr Surg Int. 2019;35:979-83.

27. Dirix M, Van Becelaere T, Berkenbosch L, van Baren R, Wijnen RM, Wijnen $\mathrm{MH}$, et al. Malignant transformation in sacrococcygeal teratoma and in presacral teratoma associated with Currarino syndrome: a comparative study. J Pediatr Surg. 2015;50:462-4.

\section{Publisher's Note}

Springer Nature remains neutral with regard to jurisdictional claims in pub-

lished maps and institutional affiliations.

\section{Submit your manuscript to a SpringerOpen ${ }^{\odot}$ journal and benefit from:}

- Convenient online submission

- Rigorous peer review

- Open access: articles freely available online

- High visibility within the field

- Retaining the copyright to your article

Submit your next manuscript at $>$ springeropen.com 